\section{El uso del cuerpo en las revistas de moda}

Valeria Stefanini Zavallo *

\begin{abstract}
Resumen: Este ensayo indaga sobre cuáles son los múltiples usos que se le da al cuerpo humano en las fotografías de revistas dedicadas a la moda, utilizando ejemplos de las revistas Vogue de España y de Estados Unidos.

Entender la relación entre el cuerpo, el espacio y los objetos nos permite acercarnos a comprender el objetivo por el que fueron producidas estas imágenes.
\end{abstract}

Palabras clave: el desnudo en fotografía - fotografía de belleza - fotografía de moda - fotografía publicitaria - géneros en fotografía - Revista Vogue.

[Resúmenes en inglés y portugués en la página 203]

\begin{abstract}
${ }^{(*)}$ Posgrado en Gestión y Administración Cultural en Artes Visuales por la Universidad de Chile, 2000. Licenciada en Artes por la Universidad de Buenos Aires, 2001. Licenciada en Historia y Teoría del Arte por la Universidad de Chile, 1997. Se desempeña como docente en la Universidad de Palermo y en la Escuela Argentina de Fotografía.
\end{abstract}

La pregunta acerca del rol del cuerpo humano en la fotografía de moda nos permite pensar en un abundante grupo de imágenes desde múltiples lugares y nos facilita acercarnos a un modo de trabajo que ha atravesado la historia de la fotografía, del diseño y de la economía desde hace más de un siglo.

La fotografía de moda es la parte más visible y familiar de un engranaje en el que funcionan en sincronía, el arte, el diseño, la industria textil y editorial y el mercado, y sostiene un interés teórico ya que son imágenes que por su intensidad y distribución forman nuestra cultura visual y marcan parámetros de apreciación en diferentes grupos sociales y momentos históricos.

En una primer mirada estamos tentados a simplificar el objeto de estudio pensando que el cuerpo es percha y exhibidor de los objetos de moda y diseño como ropas, calzado, accesorios, maquillaje, bijou y joyería, que el cuerpo no cumple otro rol que el de permitirnos apreciar estas piezas que próximamente entraran a un circuito de mercado que mueve millones de dólares en todo el mundo. Pero no hay que recorrer demasiadas páginas para darnos cuenta de que esta respuesta es insuficiente y que mostrar objetos no es más que uno de todos los requerimientos posibles a los que debe enfrentarse el cuerpo en las imágenes de una revista de moda.

El cuerpo exhibe y se exhibe, muestra, se muestra y enseña, se abre a diferentes estrategias, responde a múltiples intenciones, trabaja en cooperación con diferentes disciplinas. De la síntesis 
de todos estos requerimientos podemos entrever un modo de funcionamiento que le es propio, tanto al cuerpo fotografiado como a la fotografía en sí misma.

La revista elegida para ejemplificar los aspectos teóricos es la Vogue, pero el análisis no es excluyente y los diferentes temas pueden constatarse en otras publicaciones similares con igual intensidad.

La revista Vogue tiene su primera edición en 1892, y ya desde su origen su intención es reflejar la vida de la alta burguesía de Nueva York. La revista siempre estuvo ilustrada con la idea de representar visualmente los modos y costumbres de una clase social: su vestuario, sus lugares, sus objetos, actividades e intereses fueron el centro alrededor del que todo giró desde las tiradas iniciales. Desde muy temprano la revista desembarca en Europa; en Gran Bretaña comenzó a publicarse en 1916 y en Francia en 1924, y hoy en día se edita en más de veinte países, como: Italia, Francia, Inglaterra, Australia, Brasil, China, Alemania, Grecia, India, Japón, Corea, México, Portugal, Rusia, España, etc. En la Argentina la versión más leída es la española que llega con retraso pero todos los meses a la mayoría de los kioscos de revistas de la ciudad de Buenos Aires.

Las primeras ediciones de la revista fueron ilustradas con dibujos pero ya a principios del siglo XX se incluyeron fotografías que prontamente reemplazaron cualquier otro tipo de representación. Algunos de los fotógrafos más reconocidos en el medio han participado de las ediciones, como por ejemplo Richard Avedon, Sir Cecil Beaton, Patrick Demarchelier, Helmut Newton, Hiro, Horst, Irving Penn, entre otros muchos.

La revista Vogue, por su trayectoria, su incidencia en el mercado, y sus protagonistas nos permite trabajar distintos aspectos y miradas sobre el mismo fenómeno y nos permite responder las preguntas centrales queformulamos alver estas imágenes: ¿de quénos estáhablando una fotografía en una revista de moda? ¿Cuáles son las características particulares que nos permiten identificarlas?

\section{La fotografía de moda como género}

\section{¿Cómo funciona la noción de género en una revista de moda?}

¿Qué es una fotografía de moda en relación a todas las otras fotografías posibles?, ¿cuál es su diferencia específica dentro del inmenso mundo de fotos existentes? Estas preguntas son las disparadoras de un análisis que necesita en primer lugar explicitar el corpus en el que nos estamos adentrando.

Reconocemos una fotografía de moda pese a que no podamos precisar las notas excluyentes que la caracterizan, nos hemos familiarizado tanto con estas imágenes que ya tenemos un entrenamiento visual que nos permitiría reconocer en un grupo de fotos aquellas que pertenecen a una revista de moda, pero esto no significa que podamos definir fácilmente qué las conforma como una unidad.

La revista de moda es un hecho de la cultura de masas cada vez más presente en nuestra comunicación y es independiente del vestido de moda en sí o del objeto en sí, es por esto que podemos no ser consumidores de piezas de moda (ropa, accesorios, bijou, joyería, objetos decorativos, telas, diseños, etc.) pero necesariamente somos consumidores de todas las imágenes que se producen a su alrededor, ya sea en diferentes tipos de revistas (especializadas o no), en publicidades, en la televisión, en las vidrieras que vemos al caminar por la calle o por un 
shopping, etc. El hecho de que sean imágenes familiares y cotidianas no nos garantiza su comprensión, ni facilita su análisis, sino que en muchos casos ayuda a complicarlo y contaminarlo con múltiples elementos externos.

El primer problema que enfrentamos es establecer qué es un género y cuál es la persistencia de estas clasificaciones en la fotografía actual.

Fácilmente podemos advertir que dentro de una publicación de fotografía de moda conviven distintos géneros tradicionales, siendo los dos más importantes el retrato y el desnudo, y cuando estos géneros se producen en fotografía para incorporarse al circuito de la moda cumplen con requisitos que les son propios e identificables, podríamos decir que un desnudo de moda o un retrato de moda pueden interpretarse como sub géneros particulares. Todo lo que involucra a la fotografía de moda y se exhibe en una publicación de moda, va a funcionar con preceptos específicos. Lo plantea Roland Barthes (1989) en su análisis sobre el sistema de la moda:

[...] la fotografía de moda no es una fotografía cualquiera, tiene muy poca relación con la fotografía de prensa o la fotografía de aficionado; por ejemplo comporta unidades y reglas específicas; en el interior de la comunicación fotográfica, forma un lenguaje particular, que sin duda alguna posee su léxico y su sintaxis, sus "giros", prohibidos o recomendados (Barthes, 1989, p. 17).

Un género funciona como una categorización, funciona para unir objetos que son creados y existen independientemente entre sí, un género nos permite analizar y comprender, conformar un sistema, aunque no juegue ningún rol durante el proceso de producción de las piezas que luego serán agrupadas. Cada una de estas piezas tiene existencia por si misma, y fue creada previa e independientemente a que pensemos en una noción que las clasifique.

Las fotografías que conforman nuestro corpus de investigación han sido producidas por varios de los más considerados fotógrafos a nivel mundial, para distintas notas, concebidas por distintos directores artísticos, y han aparecido en las revistas Vogue de distintos países y momentos históricos. Más allá de todas estas diferencias particulares hay un hilo conductor.

Cada una de estas imágenes fue creada con la intención de ser única y de retratar algo que se consideraba único. Más allá de esta intención nosotros las agrupamos detectando en ellas lo común y homologable, creando categorías y géneros.

Tradicionalmente las artes plásticas han establecido consensos bastante claros acerca de lo que se puede considerar un género, si bien hoy en día estas categorías son cuestionadas o subvertidas, hay una base de acuerdo que nos permite establecer ciertas conclusiones.

En la fotografía, el concepto de género es todo menos unívoco, ya que como plantea Jean-Marie Schaeffer (2004), un género se "[...] refiere a prácticas intencionales reguladas e identificadas como tales por los creadores y los receptores." (Schaeffer, 2004, p. 16) Esta autora plantea que la fotografía puede dividirse en diferentes clases, específicamente en cuatro, teniendo en cuenta los medios técnicos utilizados (blanco y negro o color, fotografía digital, etc.), según los tipos de práctica social (arte, publicidad, comunicación, etc.), según el soporte que nos permite acceder a ella (libro, revista, exposición, etc.), según los objetos representados (familia, cuerpo, retrato, paisaje, desnudo, etc.).

Roland Barthes (1989) plantea otra clasificación posible, la primera sería la empírica (profesionales / aficionados), la segunda la retórica (paisaje / objetos / retratos / desnudos), y luego 
vendría una clasificación que él llama estética (realismo / pictorialismo). Pero el autor señala que todas estas clasificaciones a las que suele someterse la fotografía son insuficientes, ya que no le son propias, sino que sirven y han sido concebidas para otras formas de representación. Estas son algunas de todas las clasificaciones posibles en las que han sido organizadas las fotografías y más allá de las diferencias, sean sutiles o no, lo interesante es tratar de establecer cuáles son esas características que nos permiten hablar de un corpus ante todas esas imágenes que aparecen en las revistas de moda.

Sabemos que el objetivo de estas fotografías no es constituir un catálogo de objetos susceptibles de ser comprados o intercambiados, ya que algunas imágenes ni siquiera los muestran, algunas sólo nos relatan descripciones de todo aquello que ha quedado fuera de cámara, accesorios, lencería, ropa, y recurren al texto para existir ya que no se muestran. ${ }^{1}$

Una comprobación de la ruptura que se produce entre el espacio que se abre para mostrar o exhibir un objeto de moda o diseño y la producción fotográfica que finalmente aparece en una revista de moda, es la utilización del desnudo. Vamos a tomar el análisis del uso de este género como ejemplo para la comprobación de diferentes presupuestos que también pueden explicar el tratamiento de otros temas dentro de una revista de moda, como pueden ser el retrato, la fotografía interior o exterior, el uso de distintas tecnologías, etc.

El desnudo es uno de los géneros más usados en la fotografía y no es nuevo en las revistas de moda, en la Vogue el primero en aparecer fue en 1934 realizado por Edward Steichen.

El desnudo es la forma dominante de la representación del cuerpo tanto en la fotografía, como en la pintura y la escultura, y ha tenido una presencia permanente en las representaciones artísticas occidentales. Distintos estilos, épocas históricas, diferentes autores han abordado el mismo tema, que en muchos momentos fue discutido y procuró ser acotado, con el objetivo de enmarcarlo en un modelo capaz de ser aprobado social, religiosa, o moralmente.

Al definir las normativas del desnudo la Academia lo hace teniendo en cuenta que la representación debe sublimar el cuerpo y no representarlo en su materialidad, como una forma de idealizarlo. Abigail Solomon - Godeau (2004) expone cuál es la visión que Quatremére de Quincy en el siglo XVIII plantea para establecer qué ideal debe seguir la representación del desnudo:

Las formas serán modeladas con amplitud, simplificadas, purificadas, depuradas de cualquier detalle individual, de cualquier defectuosidad accidental. Las proporciones y las relaciones de las partes se fijaran con todo el rigor de una construcción matemática." “[...] evitará a toda costa intentar, con el vano pretexto de animar sus figuras, imprimirle los caracteres que en la realidad denotan vida: la flexibilidad de la carne, la transpiración de la piel, la elasticidad de los músculos. Evitará que se adivine lo que se halla bajo el envoltorio exterior, el afloramiento de la estructura ósea, los músculos y las venas, ya que todo ello no es más que detalle 'animal' (Solomon - Godeau, 2004, p. 167). 2

De Quincy nos ilustra todo lo que no debe ser mostrado, con el fin de plantearnos qué es lo que debe representar la imagen de un cuerpo desnudo, la definición trabaja por exclusión ya que la negativa es representativa de una conformación de un modelo que se caracteriza por ocultar 
o tapar, disimular lo que es propio del cuerpo en si para representar lo que en realidad sería propio de una idea o concepto.

En primer lugar está tratando de separar la llamada representación artística del desnudo, de la imagen que se considera o se usa de manera pornográfica, o que podría atentar contra los valores éticos, religiosos y morales de la época. La diferencia entre los diferentes fines que puede tener una misma imagen se centra en su capacidad de evocación erótica y de incitación al deseo. La línea muchas veces es tenue y ha llevado a profundas discusiones y esto es lo que ha alentado a muchos teóricos a tratar de establecer diferencias.

Esta manipulación de la imagen que se realizaba en la pintura, ocultando los órganos sexuales y las marcas propias del cuerpo que lo transformaban en un objeto palpitante y tibio, siempre fue difícil de trasladar a la fotografía, ya que la foto atenta contra el ideal remitiéndonos directamente a un modelo real, de existencia real, en un tiempo real.

Desde la antigüedad la representación del desnudo femenino había sido elegido como encarnación de un ideal de belleza por pintores, grabadores y escultores. Siglos después los fotógrafos siguen eligiendo a mujeres desnudas, siguen repitiendo las mismas poses, y los mismos ambientes, con la misma intención de asir algo tan escurridizo como la imagen de la belleza en sí o la representación de la feminidad.

En sus orígenes en la fotografía de revistas de moda el desnudo buscó idealizarse utilizando preceptos similares a los que habían funcionado en la pintura, por ejemplo, los desnudos frontales se disimulaban y se retocaban para no ser ofensivos, se jugaba con la luz para difuminar, con mallas color piel para cubrir, con composiciones veladas y la ayuda del blanco y negro que le restaba realismo a la escena.

Lentamente el desnudo fue cambiando y fue recién en la década del '70 cuando comenzó a tener cada vez mayor impacto visual, esto debido principalmente a la desinhibición que marcaba la época.

A partir de este momento el desnudo, total o parcial, transita las publicaciones de moda de manera habitual y siempre recurre al uso de distintos medios para estilizar, difuminar con la intensión de separar la imagen del cuerpo de un cuerpo real, pero ya no movido por un objetivo exclusivamente moralizante sino con el fin de reforzar la capacidad de idealizar y transformar esa imagen en modelo y canon. Desde los primeros efectos y juegos de luces y sombras hasta el uso del Photoshop en la actualidad el fin que motivan estas intervenciones es siempre el mismo. Siglo tras siglo la belleza se define exclusivamente por sus imágenes y no por su argumentación, no hay un correlato teórico que la sustente pero sí un álbum de imágenes que la ejemplifica y que es parte de un conocimiento general del que todos disponemos.

Pero la fotografía siempre planteó el dilema de cómo hablar de algo general cuando remite necesariamente a la existencia del particular. No es la belleza ni la mujer las que se representan en una foto sino una mujer con nombre y apellido, que tiene una existencia real en el mismo plano que todos los espectadores que la observan. Las revistas de moda usaron esa condición propia de la fotografía exaltando a la figura: la modelo, la actriz o las celebrities fueron quienes se transformaron en "modelo" de la belleza, o de la mujer, ya no su imagen o representación.

Este giro que se produce en el interior de las páginas de una revista produce un cambio en la mirada del espectador, que al ver una fotografía ve a un ser real que encarna en sí (no en su 
representación) las características idealizantes que socialmente buscamos atribuir a un modelo. El modelo socialmente a imitar ya no es una representación (que podría reunir características dispersas de distintos personajes) sino una persona, que carga sobre sí misma el peso de todas las miradas.

El nuevo rol de las figuras se ve en la revista Vogue norteamericana a partir de su era bajo la conducción de Ana Wintour que comienza a incluir en sus portadas fotografías de actrices, o cuando a partir de la década del ochenta las modelos son conocidas con nombre y apellido por el común de la gente, y más adelante cuando aparece una nueva e impensada clasificación que son los o las celebrities, figuras cuyo mérito es ser conocidas y reconocidas por el público en general. Pero el problema persiste: ¿cuáles son las fotos de desnudo que enviamos a una revista erótica, a una pornográfica, a una revista médica y a una revista de moda? ¿Cuáles son esas características que nos permiten, dentro de todas las fotos de desnudos posibles y diferentes, conocer y reconocer a las que pertenecen a una revista de moda?, y más allá de que podamos agruparlas casi de manera instintiva, ¿cómo podemos definirlas?

Como primera aproximación a una respuesta podemos decir que en la revista de moda el fin de la representación del desnudo es en primer lugar evocar un ideal de belleza y un estilo, también ideal de vida, y en segundo término plantear unos parámetros corporales que apuntan a definir el cuerpo no sólo en sentido estético sino también ético.

Esto que podemos ver en la representación del desnudo también se genera en cualquier otra fotografía que aparece en una revista de moda, como por ejemplo los retratos, sean individuales o grupales.

El cuerpo es portador de un mensaje cuyo propósito, tanto estético como ético, sobrepasa ampliamente la función puramente utilitaria que podríamos atribuirle si lo pensamos como exhibidor o percha de prendas varias, o productos diversos.

\section{Lo bello y la belleza en sí}

\section{La belleza es fotografía}

El concepto de belleza y de lo bello han ido cambiando en las diferentes épocas y lugares, pero ha tenido una forma de comunicación constante que es a través de la imagen.

La representación es el descriptor que guía entre todas las infinitas posibilidades, y hoy en día esa imagen se representa casi en forma exclusiva por medio de la fotografía, específicamente las fotografías de revistas de moda y las publicitarias. Dos géneros que crecen casi integrados y que comparten protagonistas: modelos, fotógrafos, directores creativos y de arte, diseñadores, etc. La foto nos ilustra aquello que escapa a ser descrito por medio de la palabra, y por sobre todo circula mucho mejor que cualquier texto, transformándose en la guía que usa desde la quinceañera para ingresar en la vida social y recibir la aceptación de sus pares hasta los diferentes diseñadores para comprender el movimiento de las tendencias mundiales.

Esa fotografía que se establece como definición y parámetro de belleza tiene sus propias reglas internas que la conforman y la explican.

Ya hemos planteado que uno de los fines de la utilización del desnudo en la fotografía de revistas de moda es evocar un ideal de belleza: el desnudo es la representación por excelencia del 
cuerpo bello. Abigail Solomon - Godeau (2004) plantea cómo se construye el estereotipo de belleza en el marco de una obra plástica:

El desnudo, construcción estética y artefacto de sublimación, cumple ciertos protocolos estrictos y sucede así casi desde su origen. Por definición, cuerpo ideal y no cuerpo real; siempre se ha supuesto que corresponde al ideal del cuerpo en un momento determinado de la historia. La belleza ideal, en la formulación teórica dada por el academicismo, se basa en la amalgama de distintas partes de distintos cuerpos... (Solomon - Godeau, 2004, p. 166).

Esta imagen conformada como la suma de partes distintas, en la fotografía plantea una dificultad que hoy en día se subsana desde el modelo en sí y no desde su representación. La figura misma pasa a ser la composición de diferentes partes que se agregan, se operan y se maquillan, dando paso a un nuevo tipo de canon que se manejará con diferentes presupuestos.

La creación de una imagen de belleza fue tradicionalmente la tarea de artistas, pintores, escultores y escritores que definían y representaban esos parámetros que luego eran imitados por los contemporáneos y que sobrevivieron en el tiempo, gracias a la perdurabilidad de las obras, para relatarnos los ideales que atravesaron los distintos momentos históricos.

Hoy la belleza se crea en el cuerpo mismo que la porta, y por más que socialmente es vista como encarnación de un deseo colectivo es la viva representación de un logro individual y particular, y por lo tanto tan efímera como el mismo cuerpo.

Martin Harrison (1997) recupera la cita de Sir Cecil Beaton que en 1962 ya se sorprendía de esta cualidad temporal que empezaba a marcar inexorablemente los cambios en el paradigma: "Qué imperceptible, pero rápidamente, cambia nuestra imagen de la belleza! Hasta en dos años nuestro ideal puede dar un completo cambio!... Es un fenómeno curioso que la demanda de un nuevo tipo de belleza se vea siempre cubierta" (Beaton en Harrison, 1997, p. 23). Desde la década del '60 hasta la actualidad si algo se ha modificado en este sentido es que el cambio es cada vez más rápido y voraz, y que el reemplazo esta siempre listo y a disposición para ocupar el lugar del modelo anterior.

¿Cómo analizar una concepción del cuerpo como prenda intercambiable? El cuerpo ya no es la prisión que limita el pensamiento o la libertad individual. El siglo XX no interpreta el cuerpo como coraza o restricción, sino que es el material sobre el que podemos trabajar para operar los cambios que sean necesarios, desde un simple cambio de peinado hasta un más abarcativo cambio de look. El manual de procedimientos básicos nos ofrece desde cirugías hasta maquillaje. El cuerpo pasó de ser límite a transformarse en materia creativa: el cuerpo como potencia que pone en acto nuestros más profundos anhelos.

Nada es estático, ni la forma, ni el color, puedo estirar, encoger, alargar, quitar o poner y luego dar marcha atrás y volver a empezar, si es que los criterios del ideal femenino cambian nuevamente o plantean nuevas formas a imitar.

La revista Vogue vió claramente este proceso y bajo la guía de Ana Wintour fue una de las primeras publicaciones en tratar la belleza femenina como creación. La conducción de Ana Wintour generó un cambio en el enfoque de la revista que dio paso del culto de la belleza a la creación de la belleza.

Martín Aristón señala que la frase que ha guiado una línea editorial para la revista Vogue: 
"beauties are made, not born." 3 es acuñada por la publicación paralelamente al auge de la industria cosmética. La estrategia comercial es impecable. En plena era industrial el concepto de fabricación incluye también el ideal de belleza y el ideal femenino, para demostrar que sólo pueden alcanzarse por medio del consumo de artículos suntuarios por definición, que con el correr del tiempo se multiplican hasta el infinito, y de procedimientos ya sean médicos o estéticos.

La revista no sólo acompañó este proceso sino que fue parte activa de esta modificación de hábitos y expectativas.

Vogue comienza su publicación para reflejar los gustos y aspiraciones de una reducida clase social, alrededor de un evento que se alza como hito de la conformación de un grupo, la fiesta de los Cuatrocientos, para el que cuatrocientas personas son minuciosamente seleccionadas teniendo en cuenta

...la elegancia, el porte y el comprobado desenvolvimiento social de las personas -además del dinero- para confeccionar la lista de invitados. En ese contexto nació Vogue, para ser el espejo de esos cuatrocientos elegidos, contar sus hábitos, sus formas, sus maneras de comportarse, de divertirse, las reuniones sociales en las que participaban, los lugares que frecuentaban y la ropa que lucían. Ese fue su target: "los cuatrocientos", y todos aquellos que se le querían parecer, emular y ser admitidos dentro de su exclusivo círculo ( La Nación, 2006, diciembre)..

Y justamente es el número de todos aquellos que anhelan ser parte de ese círculo el que mueve los millones de dólares de la industria de la moda y el diseño, bajo la metódica guía de todas esas imágenes que buscan mostrarles el más apropiado de los caminos a seguir.

Para este fin sirven tanto las fotografías que ilustran las notas de la revista como las fotografías de las publicidades y de algún modo podemos entender una coherencia interna dentro de la fotografía publicitaria que compite con la lograda por las fotos que conforman las notas.

Esto puede apreciarse claramente en una de las ediciones más famosas de la revista norteamericana que fue la del mes de septiembre de 2007. Esta publicación fue conocida y es recordada por ser una de las más voluminosas y porque el director de documentales R.J. Cutler acompañó y registró todo el proceso de creación, que duró cinco meses, dando origen a la película documental September Issue.

En esta edición de un total de 840 páginas, 727 son de publicidad (Página 12, 2009, octubre). Esto es un claro ejemplo de la relevancia que tiene el mercado de la moda y de la importancia que éste le asigna a la publicación de una revista, y de cómo la fotografía publicitaria y de moda pasan a ser prácticamente equivalentes. Las fotos publicitarias se organizan como notas, y para el consumidor funcionan de la misma manera.

Analizar estos dos géneros de manera integrada nos ayuda a comprender cuál es el funcionamiento interno y cómo se relacionan dentro de la revista ya que el consumidor busca extraer el mismo tipo de información de cada uno de ellos. El consumidor de una publicación de moda encuentra tanto en la fotografía producida propiamente por la revista como en las fotos publicitarias los parámetros que se establecen para la conformación de un ideal de belleza, de un ideal femenino y de un ideal de vida. 
Martín Harrison (1987) en su análisis sobre la revista Vogue, incorpora el concepto de "Beauty Photography", planteando que la mayoría de las fotografías que habitan en las revistas de moda son "fotografías de belleza", este concepto nos acerca mucho más a las imágenes que vemos en las revistas Vogue de cualquier época o ciudad. Fotografías de belleza que incluyen fotografías de moda, fotos publicitarias, desnudos, retratos, fotografías grupales, familiares, en blanco y negro o color, digitales o analógicas, y cualquier otra categorización en la que podamos pensar. Esta categoría nos indica que las imágenes se concentran en la mujer en si misma más allá de la exhibición de los objetos que se piensan comercializar, lo que usa es cambiante pero la representación de mujer de la que nos hablan no. La moda tiene temporadas pero el ser mujer es una categoría inalterable, amplia y abarcativa, que atravesará todas las estaciones y en cada una de estas consumirá distintos productos, pero consumirá al fin.

Las fotos de Vogue dicen algo sobre la belleza en sí y su concepto de belleza es una línea editorial. Esta fotografía crea un mundo en el que el cuerpo no soporta una prenda, sino que ejerce un rol, un papel, y la ropa es el vestuario que lo caracteriza para que el espectador pueda identificarlo y funciona de la misma manera que en la actuación. El cuerpo no es soporte de una prenda sino que teatraliza una historia para la fotografía, que busca narrarnos y explicitarnos una situación vital.

Roland Barthes (s/f, p. 258) ya planteó que "El teatro de la moda es siempre temático" y ese tema es la línea editorial que una revista defiende con cada publicación, el tema elegido es el mensaje al que se ajustan todos los otros elementos, las modelos como actrices, la ropa como vestuario y la locación como escenografía.

La revista Vogue plantea las notas de moda como historias ilustradas. En la fotografía de moda el mundo se fotografía como decorado, como fondo. ¿ qué relación se establece entre figura y fondo? El fondo es el contexto y marco del cuerpo, permite contextualizar una situación bastante estandarizada, la modelo aparece ya sea en el campo, en la ciudad, en un contexto industrial, disfrutando de la vida nocturna, o en la mañana en la oficina. Son las clásicas escenas en las que se sitúa una acción que ni busca ni necesita innovar para comunicarse con su destinatario tradicional que las comprende inmediatamente y las consume gracias a esa comprensión inmediata. ¿Cuál es el rol del cuerpo? El cuerpo pone en acto, mediante el gesto, mediante el talle, mediante el movimiento, mediante todo lo que muestra y todo lo que oculta el discurso.

Es una manera de dotar al mundo de la moda de un sentido más abarcativo, no sólo te digo qué ponerte, sino también en qué situaciones y cómo llevarlo. El mensaje es integral y busca ser integrador, no se trabaja sólo desde la prenda, sino desde el estilo y la tendencia.

Funciona así en la revista de moda y también en la vidriera de una tienda cualquiera, donde el maniquí soporta el peso de un cuerpo tan idealizado y tan preformateado como el de la modelo de revista, tan irreal el uno como el otro. Sinónimos de una construcción cultural de una imagen ideal de mujer y de una imagen ideal de vida, de comportamientos que no buscan tener ninguna relación ni con la mujer real y consumidora, ni con su vida concreta (porque estas ya están dadas), sino que busca establecer el vínculo con ese ideal que podemos alcanzar en alguna medida por medio del consumo.

En este entramado la prenda es lo visible, pero el objetivo es establecer valores, sentidos, usos y costumbres que guíen en el camino de una conformación de un grupo y establezcan un movimiento económico en un mercado y en una industria enorme y competitiva. 
Lo que se busca vender no es sólo ropa. No vendo ropa, ya que vender sólo ropa no es viable económicamente, no hay relación posible entre la duración de la prenda y el ritmo de crecimiento de la industria textil, lo que necesito vender es la conformación de un estilo y por sobre todas las cosas de un ritmo de cambio e intercambio.

¿Entonces qué digo cuando hablo desde una revista de moda?

Cómo ser lo que haya que ser y a que ritmo modificarlo.

\section{Notas}

1. Para este tema revisar el texto de Roland Barthes, El Sistema de la moda, que analiza justamente la moda escrita y descrita, la moda y su relación con el lenguaje articulado. "No es el objeto, es el nombre lo que provoca el deseo." (pág. 13)

2. Quatremére de Quincy fue un crítico de arte ideólogo de muchos de los preceptos de la Academia de Bellas Artes de Francia en el siglo XVIII. Esta frase esta citada en el texto de Solomon - Godeau, Abigail (2004) Género, diferencia sexual y desnudo fotográfico. Página 167 y expone algunas de las tendencias para establecer un canon para el desnudo artístico.

3. La traducción de la frase sería: "Bellas se hacen; no nacen".

\section{Referencias Bibliográficas}

Azoulay, P. (1998). Historia de la Fotografía, la fotografía de moda (CD- ROM). Francia.

Barthes, R. (1989). La cámara lúcida, notas sobre la fotografía. España: Ediciones Paidos.

Barthes, R. (s.f.). El Sistema de la Moda. Barcelona: Gustavo Gilli S.A.

Bauret, G. (1992). De la fotografía. Buenos Aires: Biblioteca de la mirada.

Eco, U. (1995). La estrategia de la ilusión. Buenos Aires: Editorial Lumen Ediciones de la Flor.

Fontcuberta, J. (1997) El beso de judas. Fotografía y Verdad. Barcelona: Gustavo Gilli S.A.

Gorodischer, V. (2009, 25 de octubre). Al diablo con el diablo. Buenos Aires, Página 12.

Harrison, M. (1987). Beauty Photography in Vogue. London: Octopus Books.

Oliva, A. y Angeletti, N.. Citados en: Planeta Vogue (2006, 24 de diciembre) Buenos Aires, Revista La Nación

Picaudé, V. y Arboizar, P. (2004). La confusión de los géneros en fotografía. Barcelona: G. Gili S.A. Saulquin, S. (1995). La moda en la Argentina. Buenos Aires: Emecé Editores.

Schaeffer, J.-M. (2004). La fotografía entre visión e imagen. En: Picaudé, Valérie y Arboizar, Phipille (2004) La confusión de los géneros en fotografía. Barcelona: G. Gilli S.A.

Solomon - Godeau, A. Género, diferencia sexual y desnudo fotográfico. En: Picaudé, Valérie y Arboizar, P. (2004). La confusión de los géneros en fotografía. Barcelona: G. Gilli S.A.

Sontag, S. (1996). Sobre la fotografía. Barcelona: Edhasa.

The Fashion Book. (1998). Phaidon: Londres

Veneziani, M. (2007). La imagen de la moda. Buenos Aires: Nobuko.

Vogue (2010, marzo y junio). España.

Vogue (2009, noviembre). Nueva York. 
Summary: This paper investigates what are the multiple uses that gives the human body in the photographs of magazines devoted to fashion, using examples of Vogue Spain and Vogue United States. Understanding the relationship between body, space and objects allows us to come to understand the purpose for which these images were produced.

Key words: advertising photography - beauty photography - fashion photography - photography Genres - The nude in photography - Vogue magazine.

Resumo: Este ensaio indaga sobre quais são os múltiplos usos que se lhe dá ao corpo humano nas fotografias de revistas dedicadas à moda, utilizando exemplos das revistas Vogue de Espanha e de Estados Unidos. Entender a relação entre o corpo, o espaço e os objetos permite-nos acercar-nos a compreender o objetivo pelo que foram produzidas estas imagens.

Palavras chave: fotografia de beleza - fotografia de moda - fotografia publicitária - géneros em fotografia - O desnudo na fotografia - revista Vogue. 